\title{
OBSERVATIONS ON THE WEB AND BEHAVIOR OF WENDILGARDA SPIDERS (ARANEAE: THERIDIOSOMATIDAE)
}

\author{
By Jonathan Coddington ${ }^{1}$ and Carlos E. Valerio ${ }^{2}$
}

\section{INTRODUCTION}

Theridiosomatidae are a small family of mostly tropical spiders that are related to the common orb-weaver family Araneidae. It is known that theridiosomatids spin modified orb-webs, but only the web of the holarctic Theridiosoma gemmosum (C. L. Koch) has been studied in any detail (McCook, 1889; Wiehle, 1931). Recently we independently discovered the unusual webs of some tropical theridiosomatid spiders that the senior author later identified as belonging to the genus Wendilgarda. The architecture and operation of these webs are unique among known spider webs. The sticky lines of the web are connected to the surface films of moving streams, and moreover are under considerable tension, more tension than can be accounted for by the action of water surface tension on an inert filament alone. The attachment of the sticky lines to the water surface is integral to the operation of the web. The sticky lines function by ensnaring insects that are themselves on the surface film of the water and are floating downstream.

\section{Materials ANd Methods}

Our observations refer to populations in Costa Rica (OTS Finca La Selva, Heredia; Punta Lloroña, Puntarenas), Guatemala (Santo Tomás, Izabal), and Honduras (Nuevo Rosario, San Juancito). Conclusive identifications of these spiders are not possible until the genus is revised (Coddington, in prep.), but our observations refer to at least three species, all of the genus Wendilgarda. Voucher specimens are deposited in the Museum of Comparative Zoology, Harvard University. Behavior of the spiders was observed by shining a headlamp obliquely at the subject and using a simple $5 \times$ handlens.

\footnotetext{
${ }^{1}$ Museum of Comparative Zoology Laboratories, Harvard University, Cambridge, Mass., 02138, USA.

${ }^{2}$ Escuela de Biologia, Universidad de Costa Rica, Costa Rica

Manuscript received by the editor June 20, 1980.
} 
The webs were observed after they had been dusted with cornstarch to heighten contrast. If there was a possibility that the cornstarch could alter the feature of the web being observed, the observations were verified on undusted webs. The accompanying photographs are all of webs that have been dusted with cornstarch, and measurements of thread lengths were taken from similar calibrated photographs of dusted webs.

Habitat. The Wendilgarda species we observed occurred above streams flowing through relatively flat areas of wet tropical forest. The streams were of moderate size, usually 3-4 m across, and 0.3-0.6 $\mathrm{m}$ in depth. Flow rates at the surface of Quebrada el Sura at La Selva averaged $2.8 \mathrm{~m} / \mathrm{sec}($ S.D. $=0.02 \mathrm{~m} / \mathrm{sec})$ on the days we observed the webs. The webs themselves were found at the edge of the stream or in the lee of a protruding snag in the stream where the flow rate is considerably less, averaging $0.13 \mathrm{~m} / \mathrm{sec}(\mathrm{S} . \mathrm{D} .=0.03 \mathrm{~m} / \mathrm{sec}$ ) at $\mathrm{La}$ Selva. Web architecture. As far as we know, the webs of Wendilgarda species are qualitatively indistinguishable in the field, and so our comments apply equally to any of the populations we observed. Each Wendilgarda web (Fig. 1a-c) consisted of a variable number of interconnecting, more or less horizontal lines of non-sticky silk. The horizontal lines connected in a dendritic pattern; closed polygonal cells of the sort typical of most other spider webs were never observed. The free ends of the horizontal lines attached directly to substrates in the web site, such as leaves or branches of overhanging plants, or woody debris in the stream itself. The webs did not have "frame lines" such as are typical of the orb-webs of other theridiosomatid genera or araneid spiders. An entire functional web may contain only one such horizontal non-sticky line or as many as six; the average number was three $(n=14$ webs). The height of the horizontal lines above the stream surface ranged from 10 to $39 \mathrm{~mm}$. They varied in length from 23 to $160 \mathrm{~mm}$, averaging $86 \mathrm{~mm}(\mathrm{n}=22$ horizontal lines). Occasionally the center of the web, or where the usually three horizontal lines intersected, was supported from vegetation above by one or two "guy lines" (Fig. 1a), but many of the webs occurred in sites with no objects immediately above the web, and, hence, with no guy lines to the web center. Usually the spider hung ventral side up on accessory lines at the periphery of the web, or hung suspended from the junction of two or more horizontal lines (Figs. 1a, 1b, 3a). 

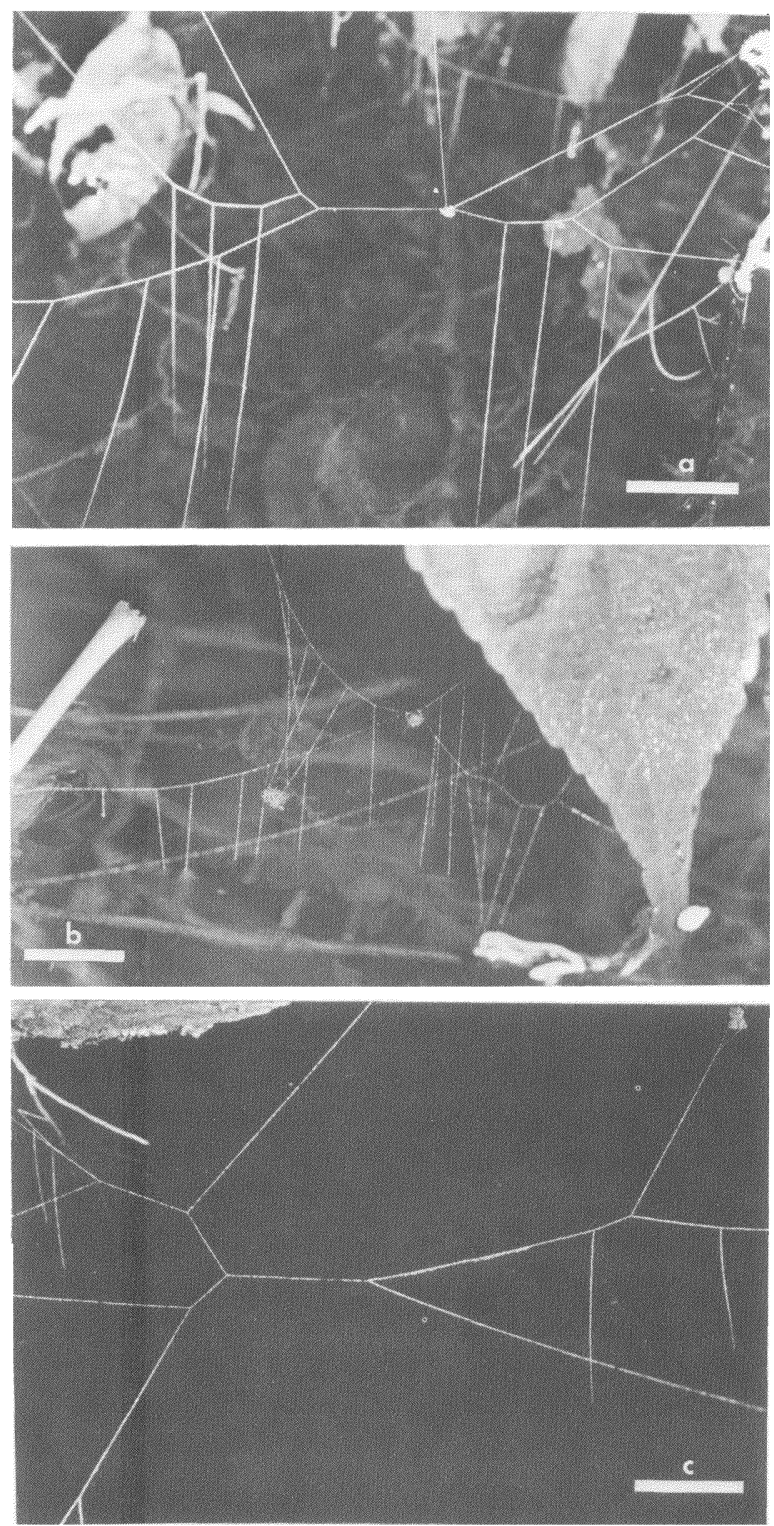

Figure 1a-c. Three examples of typical Wendilgarda webs. In Fig. 1b, at left is visible a sticky line whose junction to the water film has popped. A comparison of the resting length with more extended lengths of sticky lines in the photograph is additional evidence of the tension in the sticky lines. Photographs taken at OTS field station Finca La Selva. The webs have been dusted with cornstarch to heighten contrast. The scale lines are $10 \mathrm{~mm}$. 
Extending downward from each of the horizontal lines was a series of vertical threads made of sticky silk. The sticky silk lines never connected two horizontal lines, but only the horizontal non-sticky lines and the water surface. We observed a range of 1 to 16 vertical sticky lines per horizontal line, averaging 6 per line $(n=30$ horizontal lines). The spacing between the sticky lines along the horizontal line varied from $11 \mathrm{~mm}$ to $25 \mathrm{~mm}$, averaging $23 \mathrm{~mm}(\mathrm{n}=16$ horizontal lines), giving the whole web the appearance of several sparse combs perpendicular to the water surface. The ends of the sticky lines not attached to the horizontal lines terminated at the water surface, extending neither along the water surface nor below it to any solid object.

Sticky line-water junctions. Several experiments and observations support our observations that the lower ends of the sticky lines terminate at the surface film of the moving stream.

1. Any probe, such as a stick or pencil, may be moved between, under, and completely around the point of attachment of the sticky line to the water surface without engaging or disturbing the sticky line. This shows that none of the sticky lines extends below the water surface, that there is no bottom horizontal line that connects the ends of the vertical sticky lines, and that the sticky lines do not extend upstream or downstream for any appreciable distance from their point of attachment with the stream.

2. The probe can be moved to within 2 or $3 \mathrm{~mm}$ of the threadwater junction without snagging it, althought if it approaches too closely on the water film, the attachment point of the silk will slide toward the probe as one would expect of two free objects floating and juxtaposed on a water film. Therefore, the movement of the attachment point is not restricted.

3. If a wettable but non-porous surface, such as a leaf, is first submerged in the stream, and then slowly brought up from under the surface to intersect the sticky line attachment point, and then completely out of the stream, the sticky line will come away with the water film on the leaf behaving in every way as if it was still attached to the stream surface. If wet leaf is then re-submerged in the stream, as soon as the water film on the leaf becomes continuous with the stream surface film, the attachment point will slide off the leaf and resume its former position directly beneath the horizontal line to which it is attached.

These observations imply that even when the sticky line is attached to 
a water film on a leaf, and is completely free of the stream, it is only attached to the film, and not to the leaf itself. In this way one can observe the attachment point more closely; even under $20 \times$ magnification there are no discernible accessory lines leading away from the immediate locus of the thread. An increase in the tension on the sticky thread results in an increase in the distortion of the water film at the site of the thread junction. The water film can be pulled upward by the thread into the shape of a cone, strongly suggesting that there is some sort of interaction between the silk and the water film. If the sticky thread is now coated with cornstarch, there is a noticeable accumulation at the thread-water junction, covering essentially the area of the water film distorted by the tension in the sticky line. If a similar piece of non-sticky Wendilgarda silk is lowered into water and coated with cornstarch, no such accumulation is seen.

Web tension. Apparently the vertical sticky lines are under more tension than can be explained by the action of water surface tension on a simple inert filament. We make this conclusion based on the following observations.

1. Except in web sites where the surficial flow rate exceeds about $0.2 \mathrm{~m} / \mathrm{sec}$, the sticky lines pass straight into the stream, approximately normal to the water surface. As any fisherman has observed, inert lines with little drag on them always sag downstream in a current. The angle of the sag depends upon the drag and the current. Although increased flow rates do move the point of attachment of a sticky line downstream with respect to the horizontal line, the path described by the sticky line is essentially straight with no observable sag. This suggests that it behaves like elastic filament under a tension whose magnitude far exceeds its weight per unit length.

2. If non-sticky segments of Wendilgarda silk are immersed in the water film of the same web site from which they were collected, they behave like inert fibers: they point downstream, there is an observable sag in the aerial portion of the line, and it requires no noticeable force to pull them out of the water.

3. If the horizontal line of a Wendilgarda web is held at the point of attachment of a sticky line, and slowly raised until the waterthread junction fails, the sticky thread elongates $50 \%$ to $100 \%$ of its original length. Also, if the water-silk junction is broken artificially, and the sticky line allowed to hang under the stress of its own weight, it is typically only half the length it assumed when in 


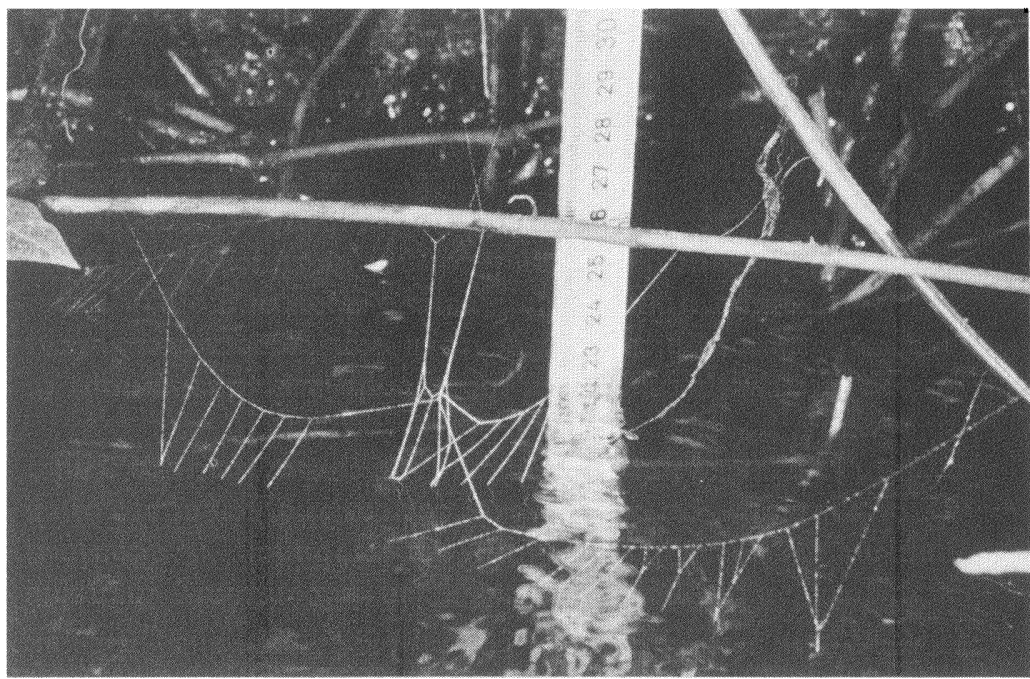

Figure 2. A Wendilgarda in fairly fast current, showing the deflection of the horizontal line due to the tension in the vertical sticky threads. Photograph taken at OTS Finca La Selva. The web has been dusted with cornstarch to heighten contrast.

the web (e.g., sticky line on left horizontal thread, Fig. 1b).

4. The horizontal line to which a series of sticky lines is attached is usually distorted by the tension in the sticky lines. When viewed in elevation, the horizontal lines look like a series of straight line segments approximating a curve, with the sticky lines connecting at the vertices of the angles between the segments (Fig. 2).

5. If the junctions between the sticky lines and the water surface are broken, the horizontal line springs upward to become essentially a straight line connecting its endpoints. In a few instances some sag in the horizontal line remained, but it was always less than before the sticky line-water junctions were severed (Figs. 3a, 3b).

6. One can clearly see the elastic response of the web to variation in the height and flow rate of the stream (Fig. 2). The stream height fluctuated naturally about $+5 \mathrm{~mm}$, and in highly tensed webs even this increase in tension was occasionally sufficient to "pop" some of the sticky lines free of the water surface.

7. Webs also popped if subjected to moderate-sized waves. In this case the leading edge of the wave apparently washed over the lower 

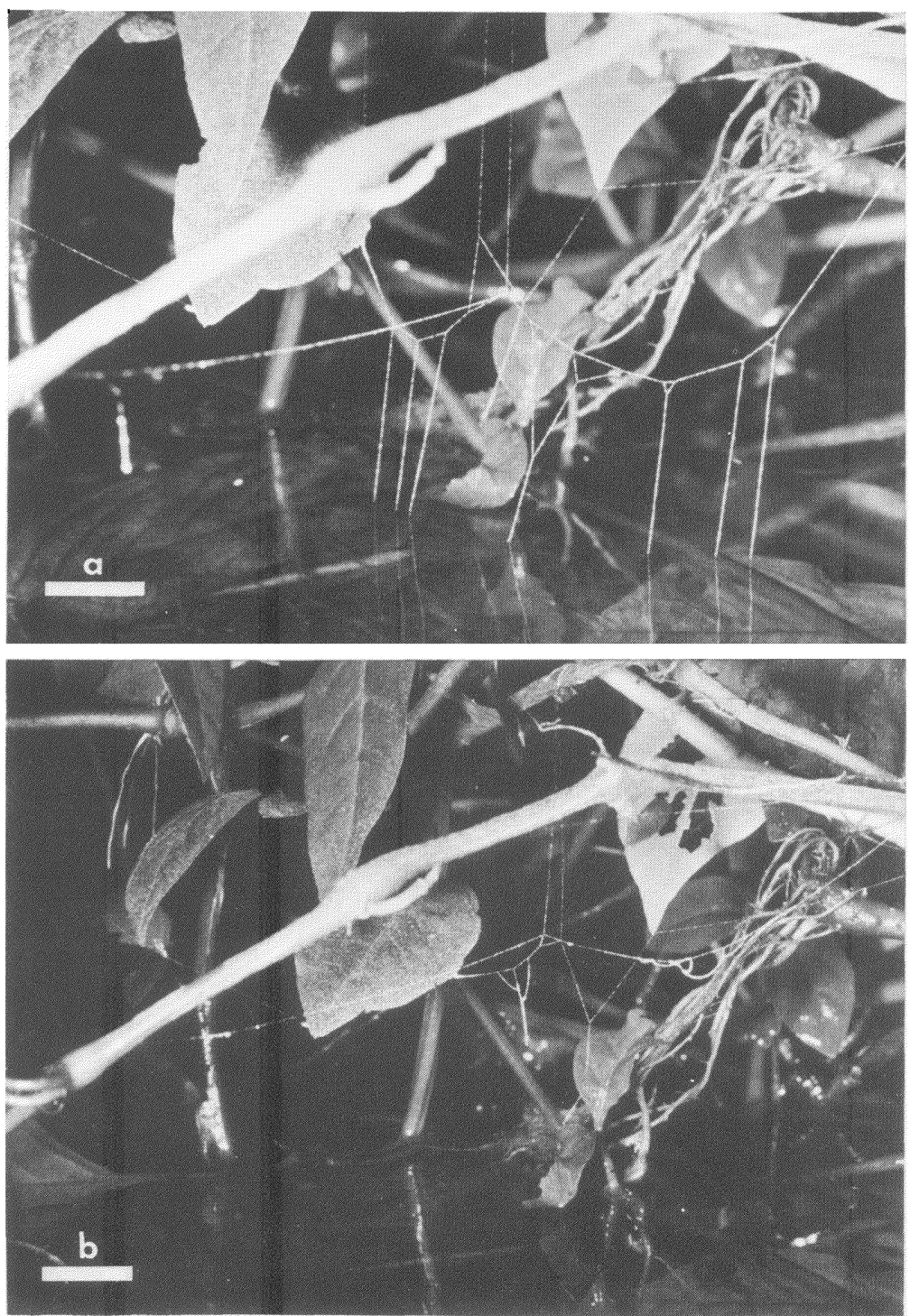

Figure 3a. A Wendilgarda web under tension opposed by the sticky line-water junctions.

3b. The same web after the sticky line-water junctions were severed, showing the decreased deflection of the horizontal line. Both webs have been dusted with cornstarch to heighten contrast. The scale lines are $10 \mathrm{~mm}$. 
segments of the sticky lines but the water remained fastened to the highest point on the line it reached. Hence when the stream returned to its normal height, the sticky lines were under excessive stress and the water junction failed.

\section{Web Function and Behavior of the SPIDeR}

Web function. We were never fortunate enough to witness the complete natural sequence of prey capture by Wendilgarda spiders. However, Figure 4 is a photograph of an insect exuvium which floated downstream and contacted one of the sticky lines of a Wendilgarda web. The exuvium was dry, and merely resting on the surface of the water. It initially touched only one of the sticky lines. Apparently the lines adhere preferentially to cuticle in comparison to water, because it seemed that on contact the line stuck to the exuvium while the sticky line-water junction broke. Fastened to the web by the single sticky line, the exuvium oscillated back and forth in the current until, in the space of a few seconds, it contacted several other sticky lines. At this point we dusted the web to photograph the event. Attack behavior. Portions of the attack behavior of Wendilgarda spiders can be elicited by vibrating a sticky line or the water next to it with a tuning fork. The response of the spider is fairly sterotyped and follows one of two patterns.

1. The spider may move rapidly along the horizontal line to a point above the tuning fork and reel in the sticky line until the sticky line-water junction breaks. This action involves considerable deflection of the horizontal line. The spider then hauls up the sticky line and searches the space around the end for a few seconds, rolling up the line and turning it over with its first two pairs of legs. After a variable length of time, the spiders usually reversed direction and returned to the center or periphery of the web. In the case where the tuning fork is actually stuck to the sticky line, the spider by pulling on the sticky line would pull itself and the horizontal line down the entire distance to the water surface. It then would palpate the tuning fork with its first two pairs of legs, and apparently attempt to bite the tuning fork.

2. In about half the number of presentations of the tuning fork, however, the spider did not simply move along the line toward the stimulus. The initial response of the spider was to cut the horizontal line at some point fairly close to its connection with the 


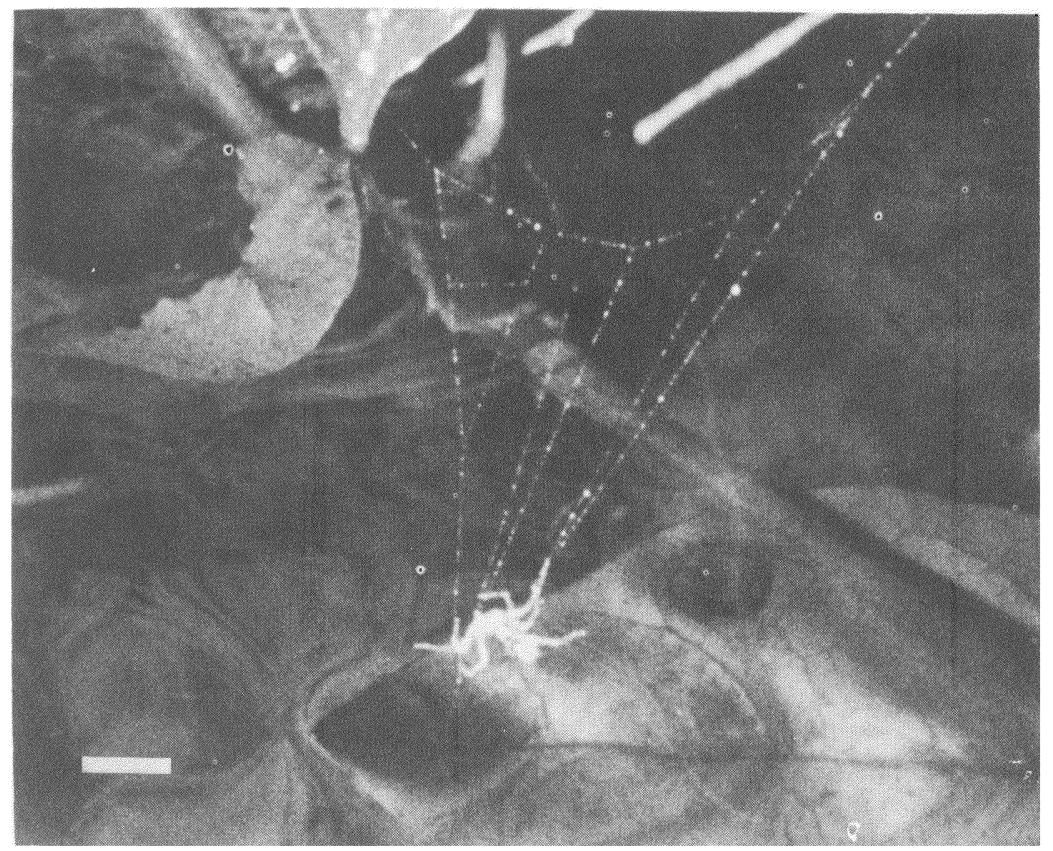

Figure 4. An insect exuvium caught in a Wendilgarda web. The web has been dusted with cornstarch to heighten contrast. Scale $5 \mathrm{~mm}$.

other horizontal lines composing the web. It would then attach a new silk line to the web behind it, and progress towards the stimulus by pulling itself along the old horizontal line, reeling up the old line as it went. The disposition of old and new silk is only possible if the web has been lightly dusted with cornstarch before the spider starts to spin the new horizontal line. With this treatment, the old line is dusted and therefore visible while the new line is very difficult to see. It is possible that the presence of cornstarch on the web affects the spider's behavior, but when the same attack sequence was seen on unstarched webs the movements of the spider's legs appeared comparable. We have no observations to suggest that the actions of spiders on dusted and undusted webs differ for this particular behavioral sequence.

This pattern of approach on the horizontal line is significant because the spider did not reel in the sticky lines of the web as it progressed, but only the horizontal segments between them. 
Consequently, as the spider reeled up the horizontal line segment between sticky lines, the two sticky lines gradually approached each other and eventually coalesced into one doubled sticky line, still attached to the water surface. The spider would thus "snowplow" toward the stimulus, carrying an increasing number of coalesced sticky lines forward with it. Eventually, when the spider reached the sticky thread transmitting the vibration, the coalesced mass of sticky threads, still attached to the water surface, would simultaneously contact the "prey". One can infer from this type of approach behavior that the contact of the prey with one or two sticky lines alerts the spider to the presence of prey in the web and initially restrains the prey. However, the retention capabilities of the web are tremendously increased by the contact between the prey and the composite sticky "rope" accumulated by the spider as it approaches the site. Because the number of intervening lines can be substantial, the probability of the prey escaping is reduced, and the spider may gain time before it has to commit itself to subduing the entangled animal.

We tried on several occasions to introduce prey into webs, but because of the complex current patterns in the sites in which the spiders built their webs, we were successful in only one instance. Here the spider was initially at the center of the web. It first oriented toward the horizontal line concerned and twitched the line several times with a rapid flexion of its first two pairs of legs. It then "snowplowed" toward the ensnared ant, reached the sticky line connected to the ant, and pulled itself and the horizontal line to the ant by reeling in the sticky "rope." It then palpated the ant with the first pair of legs, dropped its hold on the sticky "rope," reeled in the next horizontal line segment, and finally cut free the sticky "rope" to which the ant was attached.

Web building. We have observations of several sequences of web construction, but need more information before the significance of the spider's movements in the larger context of the behavior of other theridiosomatid genera or araneoid families can be reliably interpreted. Our preliminary comparative studies suggest that the webbuilding behavior of Wendilgarda species can be homologized to that of Theridiosoma species, and that the non-sticky and sticky lines of the Wendilgarda web are homologous to the radii and viscid spirals of the theridiosomatid orb-web (Coddington, in prep.).

Wendilgarda spiders may rebuild their webs as often as three times 
in twenty minutes. It takes them an average of four minutes to build a web, and as little as one minute to construct the sticky lines for any one horizontal line. This rate of web replacement is unusually high among spiders, but is apparently necessary in the constantly changing environment in which Wendilgarda spiders build. As described above, the normal vagaries of stream current and height are often sufficient to pop sticky line attachments and consequently to render webs ineffectual.

Of more interest, perhaps, are the overall large fluctuations to which many of these tropical streams are subject. Quebrada el Sura at La Selva, for example, routinely fluctuates a meter or more in height in response to the frequent rains, and, during more intense storms has raised 4-5 meters above its normal height, with a concomitant increase in flow rate (Thomas Ray, Cathy Andrews, pers. comm.). There is an obvious question as to where Wendilgarda spiders go during such high water periods. It is possible that they spin retreats on shore at the normal level of shoreline and simply wait out the flood under water, but, given the violence of the floods, it seems more likely that they would have to move to dry ground in order to survive. During major storms the distance involved could easily amount to ten meters. However, despite extensive searches we never found Wendilgarda spiders with webs on dry land. What taxes in the behavior of the spider permit such movement, or the relocation of the stream after a storm, are unknown.

\section{Discussion}

There is reason to suspect that all species of Wendilgarda spin such webs. Eugène Simon saw webs of Wendilgarda theridionina Simon in Venezuela. In 1895 he wrote: “... the web of Vendilgarda [sic], strung beneath the vault of humid rocks, which overhang torrents and pools, is a small, very elementary network, composed of a few threads radiating with little regularity, offering only the vaguest lineaments of a orb web." (p. 916). Petrunkevitch (1930), describing the web of the same species in Puerto Rico wrote: "Spiders of both sexes live in dense woods, spinning their threads between rocks over brooks. These threads are so fine that it is impossible to see them, and the spider has the appearance of being suspended in the air without any support" (p. 301). It also is possible that Petrunkevitch was observing the web of $W$. mexicana Keyserling, since the species are difficult to 
distinguish. Last, Fritz Vollrath collected what is probably $W$. galapagensis Archer from the Cocos Islands off the coast of Costa Rica, and noted on his collecting label, "second growth, single thread." Currently, there are five other neotropical species placed in Wendilgarda. Of these, two are apparently known only from the type specimens, and the webs of none of these species are described. Although it is likely that a few of these names may have to be placed in synonymy when the genus is revised, we predict that all species of Wendilgarda will be found to spin these peculiar webs.

Wendilgarda species have evolved a web that exploits a hitherto unknown property of silk fibroins. Obviously, the chemical nature of the silk, or silks, composing the sticky lines of Wendilgarda webs and their glandular source, as well as the molecular details of the silkwater junction are extremely important in the function of the web and require further study. Such facts as the amount of tension the web is normally under, or the amount it will maximally sustain, are being investigated. In addition, the relationship of the Wendilgarda web to the modified orb-webs constructed by other members of the family, and the behavior patterns used to construct it, may allow inferences about the evolution of the web architecture that so precariously straddles the terrestrial and aquatic environments.

\section{SUMMARY}

We describe the web of the spider genus Wendilgarda. The webs of the three species thus far are indistinguishable in the field. They consist of a dendritic pattern of non-sticky horizontal lines spun above the surfaces of moving streams. Extending from the horizontal non-sticky lines are vertically oriented sticky lines that terminate at the surface of the stream. The ends of the vertical sticky lines are attached only to the surface film of the stream. The entire web is under considerable tension, and the tension is opposed by the sticky line-water function. We describe how the web functions, how it it used in the attack behavior of the spider, and suggest that the architecture of the Wendilgarda web can be related to the modified orb-webs characteristic of other theridiosomatid spiders. 


\section{ACKNOWLEDGEMENTS}

We would like to acknowledge the support of the Richmond Fund of Harvard University and an Organization of Tropical Studies RIAS grant to the senior author, which supported part of this research. We would also like to thank Dr. Herbert W. Levi, Dr. Robert M. Woollacott, Ms. Cecilia Lenk, and Mr. Mark Stowe for their comments on earlier drafts of the manusript.

\section{Literature Cited}

McCook, H. D.

1889. American Spiders and their Spinningwork, vol. 1. Philadelphia (published by the author).

Petrunkevitch, A.

1930. The Spiders of Puerto Rico, part II. Trans. Conn. Acad. Arts \& Sci. 30: 159-355.

Simon, E.

1885. Histoire naturelle des Araignées, vol. 1, 2nd ed. Édouard Duruy, Paris. Wiehle, $\mathrm{H}$.

1931. Araneidae, in F. Dahl, Die Tierwelt Deutschlands, 23: 1-136. 

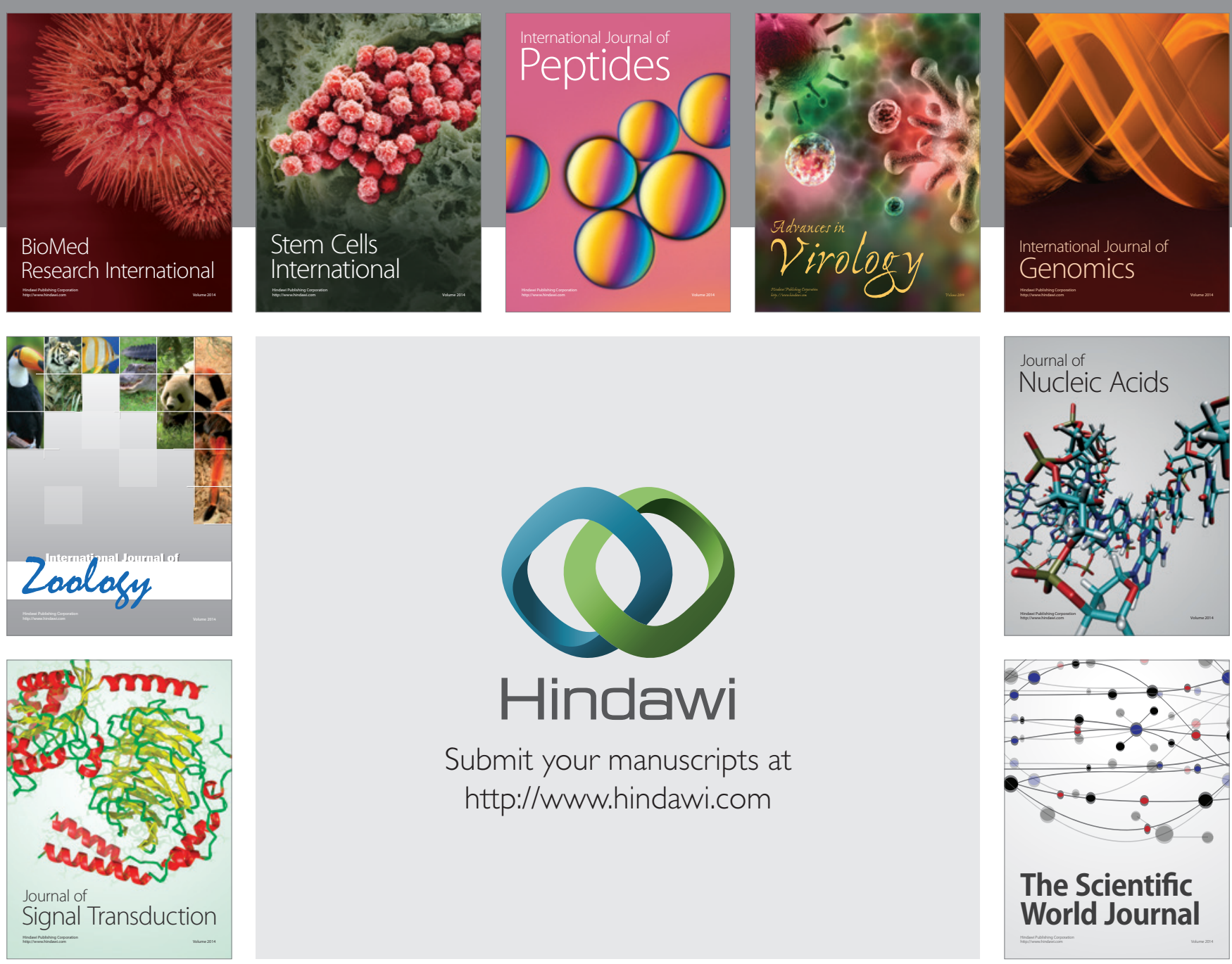

Submit your manuscripts at

http://www.hindawi.com
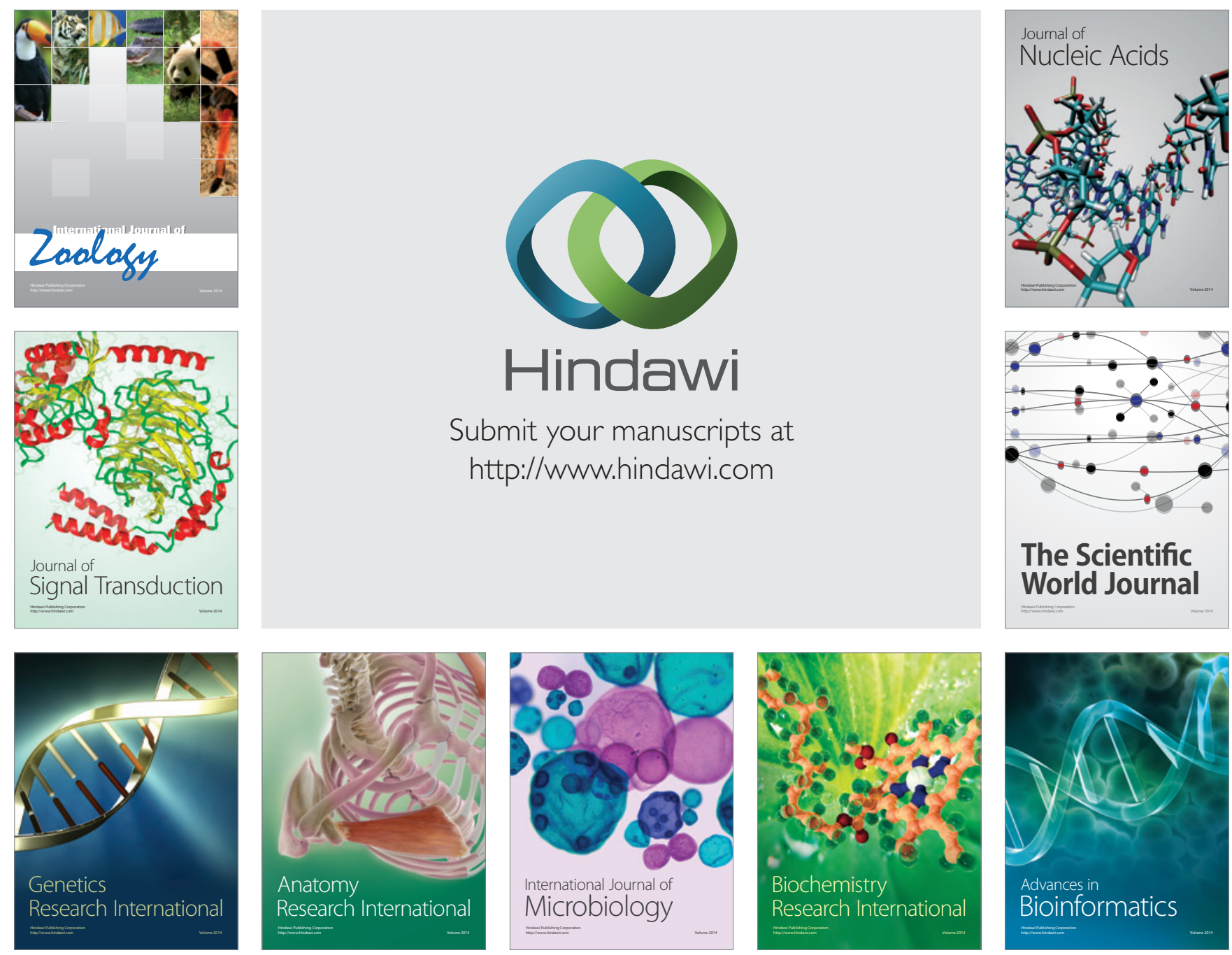

The Scientific World Journal
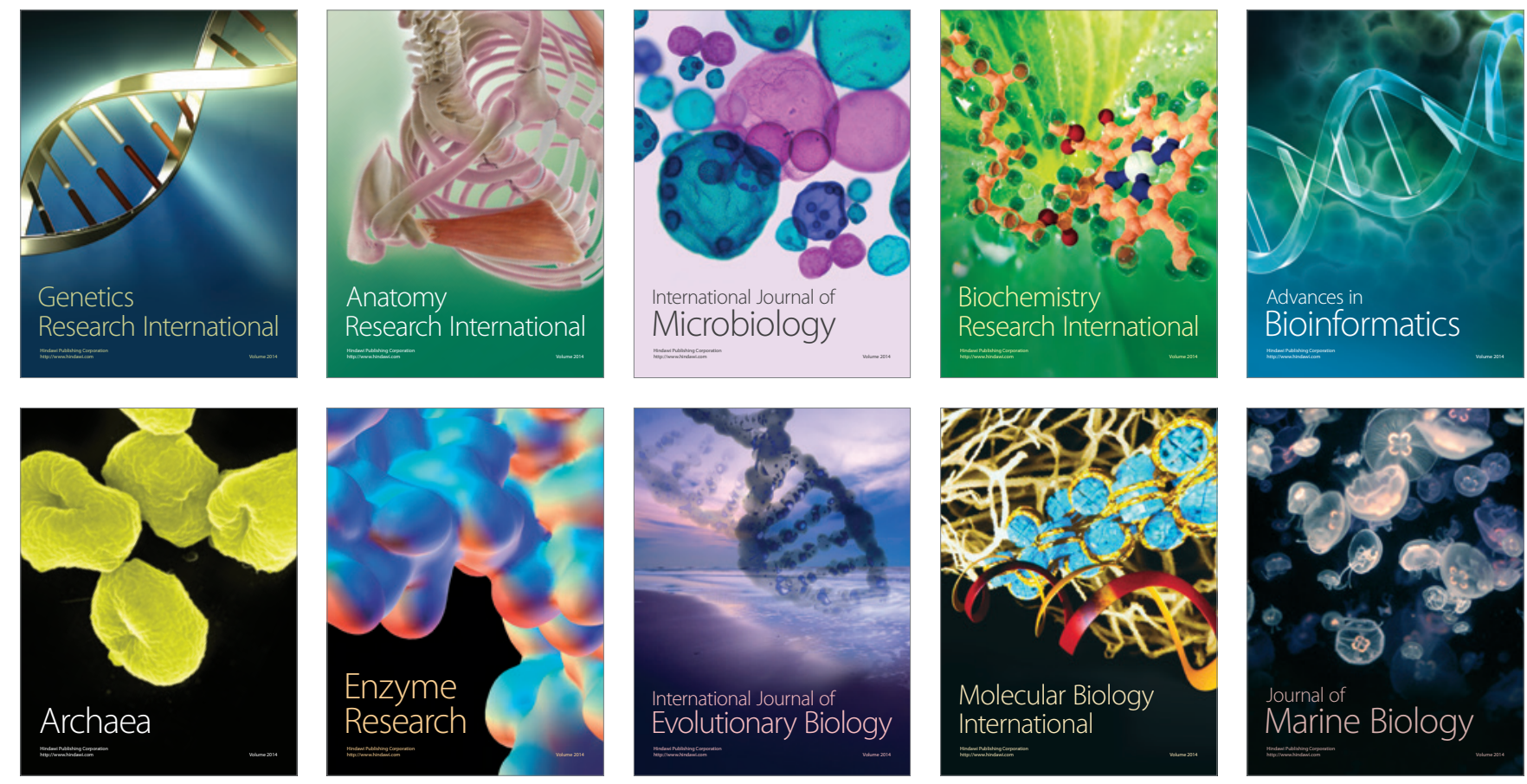